adverse events (headaches $\mathrm{n}=8$, nausea $\mathrm{n}=2$, abdominal pain $\mathrm{n}=2$, chest pain $\mathrm{n}=1$, chills $\mathrm{n}=2$, dyspnea $\mathrm{n}=3$, myalgias $\mathrm{n}=3$, pruritis $\mathrm{n}=4$, fatigue $\mathrm{n}=3$, and rash $\mathrm{n}=5$ ).

\begin{tabular}{llllll}
\multicolumn{5}{l}{ Abstract FRI0009 Table 1} \\
\hline & HAQ & $\begin{array}{l}\text { Stiffness } \\
\text { (minutes) }\end{array}$ & $\begin{array}{l}\text { Pain (VAS- } \\
\text { cm) }\end{array}$ & $\begin{array}{l}\text { Swollen joint } \\
\text { count }\end{array}$ & $\begin{array}{l}\text { Tender joint } \\
\text { count }\end{array}$ \\
\hline Baseline & $1.95 \pm$ & $92 \pm 88$ & $6.4 \pm 2.5$ & $13.21 \pm 11$ & $13.7 \pm 11.8$ \\
& 0.6 & & & & \\
6 & $1.22 \pm$ & $56 \pm 75$ & $4.9 \pm 3.0$ & $11.5 \pm 10.9$ & $10.5 \pm 10.2$ \\
months & 0.7 & & & & \\
p value & 0.0002 & 0.13 & 0.07 & 0.29 & 0.07 \\
\hline
\end{tabular}

Conclusion Infliximab is often used in more difficult RA patients (older, long-standing RA, multiple DMARD failures). This referral pattern may explain the increased incidence of adverse events and suboptimal clinical response noted in our cohort. However, our results suggest a trend towards rapid, clinically important improvement in measures of disease activity. Ongoing follow-up of this growing group of patients will provide necessary information regarding the appropriate role of infliximab in the treatment of RA.

\section{FRI0010 EFFECT OF OSTEOPROTEGERIN AND PAMIDRONATE TREATMENT IN TRANSGENIC MICE OVEREXPRESSING HUMAN TNF-ALPHA}

${ }^{1} \mathrm{~K}$ Redlich, ${ }^{2} \mathrm{~A}$ Maier, ${ }^{1} \mathrm{~S}$ Hayer, ${ }^{3} \mathrm{G}$ Kollias, ${ }^{4} \mathrm{CR}$ Dunstan, ${ }^{5} \mathrm{~S}$ Lang, ${ }^{6} \mathrm{~W}$ Woloszczuk, ${ }^{1} \mathrm{G}$ Steiner, 'I Smolen, 'G Schett. 'Internal Medicine III, Division of Rheumatology; ${ }^{2}$ Department of Radiology; ${ }^{3}$ Department. of Molecular Genetics, Hellenic Pasteur Institute, Athens, Greece; ${ }^{4}$ Department of Pathology, Amgen, Inc., California, USA; ${ }^{5}$ Department of Pathology; ${ }^{6}$ Ludwig Boltzmann-Institute of Exp. Endocrinology, University of Vienna, Vienna, Austria

10.1136/annrheumdis-2001.1139

Background Rheumatoid arthritis (RA) is characterised by progressive joint destruction resulting from chronic inflammation. Recent studies suggest that bone-resorbing osteoclasts formed in the synovium play an important role in bone destruction in RA. Objectives We studied the effect of anti-resorptive treatment with osteoprotegerin and/or pamidronate compared to TNF blockade with infliximab on the development of erosions in TNF overexpressing mice.

Methods Systemic treatment with osteoprotegerin (OPG), pamidronate, both osteoprotegerin and pamidronate, infliximab or phosphate buffered saline (PBS) was carried out by intravenous injection. Treatment was initiated at the time of onset of arthritis and continued over $35 \mathrm{~d}$. Clinical, serological, radiological and histological outcomes were assessed after treatment.

Results Clinical improvement, as assessed by reduction in paw swelling was only seen in the infliximab treated group. X-Rays of the hind paws were performed to quantify erosive changes. Erosions were detectable in each joint compartment Grading of erosions was performed analogous to the Larsen score. There was a marked and significant $(\mathrm{p}<0.05)$ reduction in the Larsen scores of mice treated with OPG (-54\%), OPG and pamidronate $(-64 \%)$ and infliximab (-66\%). Microscopic examination of decalcified joint tissue sections using a semiquantitative method, revealed a significant $(\mathrm{p}<0.05)$ reduction in the extent of erosions in all treatment groups (OPG: $-56 \%$; pamidronate: $-53 \%$;
OPG + pamidronate: $-81 \%$; infliximab ?46\%) when compared to controls.

Conclusion These data suggest that anti-resorptive treatment may have a significant potential in TNF-mediated bone destruction.

\section{FRI0011 THE EFFECT OF STEROID INJECTION AFTER ARTHROSCOPIC SYNOVECTOMY IN RHEUMATOID KNEE SYNOVITIS}

SI Kuzmanova, PC Solakov, AN Atanasov, SA Andreev, K Klinkanov. Rheumatology, Medical Faculty Hospital, Plovdiv, Bulgaria

\subsection{6/annrheumdis-2001.1140}

Background The study assesses the therapeutic result from a single application of local corticosteroid (betamethasone $7 \mathrm{mg}$ ) seven days after the performance of an arthroscopic synovectomy of the knee joint in patients with rheumatoid arthritis (RA).

Objectives An arthroscopic shaver-synovectomy with a consecutive tidal lavage with $4-5 \mathrm{~L}$ saline was performed in $73 \mathrm{RA}$ patients $(51 \mathrm{~F} / 22 \mathrm{M})$ with mean disease duration $4,5( \pm 1.8)$ years and active synovitis of the knee joints. In 23 patient $(15 \mathrm{~F} / 8 \mathrm{M})$ after the arthroscopic synovectomy (AS) an application of a local corticosteroid was not performed (control group).

Methods The assessment of the results was done on 1st, 3rd and on 6th month after AS according to the Knee Society Rating System, using a scale for assessment of the knee joint in respect of the changes of the pain, range of motion (ROM), joint stability and some functional parameters.

Results A higher degree of reducing of the pain, improvement in the joint stability of the gait and of the ability of climbing and descending scales in all patients with local application of corticosteroid after AS was found compared to controls $(\mathrm{p}<0.001)$

Conclusion The results confirm the better effect from the administration of a local corticosteroid one week after an arthroscopic synovectomy in rheumatoid knee synovitis.

\section{REFERENCES}

1 Sharma A, Baethge BA, Acebes JC, et al. Arthroscopic lavage treatment in rheumatoid arthritis of the knee. J Rheumatol. 1996;23(11):1872-4

2 Srinivasan $A$, Amos $M$, Webley $M$. The effect of joint washout of steroid injection compared with either joint washout of steroid injection alone in rheumatoid knee effusion. Br J Rheumatol. 1995;1:219-27

\section{FRI0012 ADVERSE EVENTS, DRUG WITHDRAWAL AND EFFICACY OF LEFLUNOMIDE IN UNSELECTED OUTPATIENTS WITH RHEUMATOID ARTHRITIS}

${ }^{1} \mathrm{~L}$ Mourad, ${ }^{1} \mathrm{EN}$ van Roon, ${ }^{2} \mathrm{TL}$ Jansen, ${ }^{2} \mathrm{PM}$ Houtman, ${ }^{2} \mathrm{GA}$ Bruyn, ${ }^{2} \mathrm{EN}$ Griep, ${ }^{1}$ WA Baars, ${ }^{3} \mathrm{JR}$ Brouwers. 'Department Clinical Pharmacy; ${ }^{2}$ Department Rheumatology, Medisch Centrum Leeuwarden, Leeuwarden; ${ }^{3}$ Department of Social Pharmacy and Pharmacoepidemiology, State University of Groningen, Groningen, The Netherlands

\subsection{6/annrheumdis-2001.1141}

\section{Background}

Objectives Leflunomide (LEF) is a disease modifying antirheumatic prodrug with immunomodulating, antiproliferative and antiinflammatory properties. We studied our first daily practice experience with LEF in the Outpatient Department of Rheumatology.

Methods In this prospective study we included all consecutive patients with active rheumatoid arthritis (RA), starting treatment 
with LEF from February 2000 to January 2001. From patient records data were collected, like patient characteristics, medication data and Disease Activity Scores (DAS28). Analysis was performed on intention to treat basis. Primary endpoints are occurrence of adverse events possibly related to LEF use, incidence and reasons for LEF withdrawal and change in DAS28.

Results 110 patients ( $\mathrm{n}=38$ men and $\mathrm{n}=72$ women), mean age (SD) 65 (13) years and a median disease duration of 5.5 years were included; mean follow up (SD) was 170 (91) days. Last DMARD prescribed prior to LEF was methotrexate (MTX) 28\%, sulfasalazine (SASP) 25\%, hydroxychloroquine (HCQ) $18 \%$ and others $10 \%$; $19 \%$ of the patients used LEF as first DMARD. Mean number of DMARDs prescribed before starting LEF was $1.8 \pm 1.4$. In $9 \%$ of the patients LEF was given in combination with another DMARD [MTX (6\%), HCQ (2\%) or SASP (1\%)]. Adverse events (AE) possibly related to LEF use occurred in $56 \%$ of patients during follow up, most frequently involving the gastrointestinal tract (62 AE) and skin (21 AE). During follow up $27 \%$ discontinued LEF, $16 \%$ due to side effects, $5.5 \%$ due to inadequate response, $4.5 \%$ due to a combination of both. For $1 \%$ an undefined cause for withdrawal was recorded. The incidence density for withdrawal of LEF treatment is 56.6 per 100 patient years. Using the change in DAS28 as an efficacy parameter, at the first follow up visit (mean two months) after starting LEF, 22\% were categorised good, $48 \%$ moderate and 30\% non responder. At the second visit (mean six months) $26 \%, 42 \%$ and $31 \%$ were categorised good, moderate or non responder.

Conclusion In an outpatient rheumatology practice the incidence density per patient year for withdrawal of LEF treatment is high. Adverse events were the most frequent reasons for withdrawal; gastro-intestinal tract and skin being the organ (systems) most frequently involved. Using the change in DAS28 as efficacy parameter at the sixth month $68 \%$ were categorised as good and moderate responders to LEF.

\section{FRI0013 OPEN-LABEL EVALUATION OF THE EFFICACY AND SAFETY OF ETANERCEPT IN COMMON RHEUMATOLOGY USAGE (ECRU)}

${ }^{1} \mathrm{M}$ Herold, ${ }^{2} \mathrm{~A}$ Aytekin, ${ }^{3} \mathrm{G}$ Klein, ${ }^{2} \mathrm{~J}$ Nowak, ${ }^{4} \mathrm{~W}$ Siegmeth, ${ }^{5} \mathrm{U}$ Stuby. ${ }^{1}$ Int. Med., Uniklinik, Innsbruck; ${ }^{2}$ Med. Department, Wyeth Lederle, Wien; ${ }^{3}$ SKA, Saalfelden; ${ }^{4} S K A$, Baden; ${ }^{5}$ Med. Department, LKH, Linz, Austria

\subsection{6/annrheumdis-2001.1142}

Background Tumour Necrosis Factor-alpha (TNF $\alpha$ ) plays an important role in the inflammatory processes of RA and the resulting joint pathology. Etanercept is a dimeric fusion protein consisting of two p75 TNF $\alpha$ receptors linked to the Fc portion of the human IgG1. This protein can bind and inactivate up to two free molecules of TNF $\alpha$. The safety and efficacy of etanercept has been demonstrated in human clinical trials of early RA and active RA.

Objectives The Primary efficacy variable was the proportion of patients achieving 20\% improvement in symptoms according to American College of Rheumatology (ACR) response criteria at Week 16. Patients were evaluated clinically for adverse events at each visit.

Methods This study was conducted in 55 Austrian outpatients with active RA who have failed at least one disease-modifying anti-rheumatic drug (DMARD). Each patient received twiceweekly subcutaneous injections of etanercept $25 \mathrm{mg}$ administered over a treatment period of 16 weeks. Stable doses of methotrexate (MTX) and steroids were permitted. A clinical assessment of the patient's response to therapy and safety assessments were performed at each regular visit.

Results Efficacy: At week 16, 80\% of the patients achieved an ACR 20 response (primary outcome measure). Moreover, 45,5\% of patients achieved an ACR 50 response and 10,9\% patients achieved an ACR 70 response at week 16 .

The mean number of swollen joints fell from 17 at baseline to 6,7 at week 16 . The mean number of tender joints fell from 18,9 at baseline to 7,1 at week 16 .

The mean score of Patient's Global assessment fell from 6,6 at baseline to 2,9 at week 16 . The mean score of Physician's Global Assessment score fell from 6,5 at baseline to 2,7 at week 16.

Safety: Etanercept $25 \mathrm{mg}$ twice weekly was well tolerated. Adverse Events were primarily mild injection site reactions.

\section{Conclusion}

- This was an open-label, uncontrolled, 16 week study conducted in 55 Austrian RA patients for whom DMARD therapy was inappropriate or ineffective. Stable doses of MTX and steroids were allowed.

- The percentage of patients with an ACR 20 response in the present study $(80 \%)$ is slightly greater than that reported in prior large multicentre studies (range 70 $75 \%$ ).

- No unusual patterns of AEs were identified.

- The safety and efficacy of etanercept $25 \mathrm{mg}$ s.c. twice weekly in a single European country in a naturalistic, "common usage" setting were similar to that observed in controlled clinical trials in the US and EU.

\section{FRI0014 FACTORS PREDICTING METHOTREXATE TOXICITY}

${ }^{1} \mathrm{M}$ Hoekstra, ${ }^{2} \mathrm{~A}$ Van Ede, ${ }^{1} \mathrm{C}$ Haagsma, ${ }^{1} \mathrm{M}$ Van de Laar, ${ }^{2} \mathrm{R}$ Laan. ${ }^{1}$ Department of Rheumatology, Medisch Spectrum Twente, Enschede, The Netherlands; '2Department of Rheumatology, University Hospital St Radboud, Nijmegen, The Netherlands

10.1136/annrheumdis-2001.1143

Background Methotrexate is the most effective treatment in rheumatoid arthritis. The treatment is limited by adverse events. Gastro-intestinal toxicity and hepatotoxicity occur the most. Various different factors have been reported to contribute to methotrexate toxicity.

Objectives To determine predictive factors for developing methotrexate toxicity, and methotrexate withdrawal because of toxicity.

Methods Data from a double-blind placebo controlled multicenter study on patients with active rheumatoid arthritis were used.

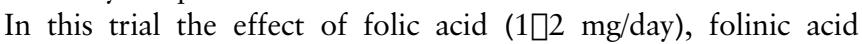
(2.5 mg/week) and placebo along methotrexate therapy (7.5maximum $25 \mathrm{mg} /$ week) was compared. The patients never had methotrexate before, had active disease and a creatinine clearance $>50 \mathrm{ml} / \mathrm{min}$. The three groups contained 133, 141 and 137 patients respectively. The follow-up was 48 weeks.

By means of multiple stepwise regression analysis we studied the relation between baseline variables and the following: hepatotoxicity (ALAT $>3 \times \mathrm{ULN}$ ), the ten most frequent subjective adverse events, and methotrexate withdrawal because of toxicity.

With the different toxicities we studied specific independent factors, for example NSAID's and alcohol use in hepatotoxicity.

Results Hepatotoxicity:

We found a significant association between folate suppletion and lack of hepatotoxicity ( $\mathrm{p}<0.0001$ ). Smoking was negatively associated with hepatotoxicity, with less hepatotoxicity when the patient smoked $(\mathrm{p}=0.003)$. 